\title{
Increased interictal cerebral glucose metabolism in a cortical-subcortical network in drug naive patients with crytogenic temporal lobe epilepsy
}

Massimo Franceschi, Giovanni Lucignani, Angelo Del Sole, Chiara Grana, Sergio Bressi, Fabio Minicucci, Cristina Messa, Maria Paola Canevini, Ferruccio Fazio

\begin{abstract}
Positron emission tomography with $\left[{ }^{18} \mathbf{F}\right]-$ 2-fluoro-2-deoxy-D-glucose ([ ${ }^{18}$ F]FDG) has been used to assess the pattern of cerebral metabolism in different types of epilepsies. However, PET with $\left[{ }^{18}\right.$ F]FDG has never been used to evaluate drug naive patients with cryptogenic temporal lobe epilepsy, in whom the mechanism of origin and diffusion of the epileptic discharge may differ from that underlying other epilepsies. In a group of patients with cryptogenic temporal lobe epilepsy, never treated with antiepileptic drugs, evidence has been found of significant interictal glucose hypermetabolism in a bilateral neural network including the temporal lobes, thalami, basal ganglia, and cingular cortices. The metabolism in these areas and frontal lateral cortex enables the correct classification of all patients with temporal lobe epilepsy and controls by discriminant function analysis. Other cortical areas-namely, frontal basal and lateral, temporal mesial, and cerebellar cortices-had bilateral increases of glucose metabolism ranging from 10 to $15 \%$ of normal controls, although lacking stringent statistical significance. This metabolic pattern could represent a pathophysiological state of hyperactivity predisposing to epileptic discharge generation or diffusion, or else a network of inhibitory circuits activated to prevent the diffusion of the epileptic discharge.
\end{abstract}

(F Neurol Neurosurg Psychiatry 1995;59:427-431)

Keywords: epilepsy; cryptogenic temporal lobe epilepsy; refractory epilepsy; PET/ $\left[{ }^{18} \mathrm{~F}\right] \mathrm{FDG}$

Cryptogenic partial epilepsies are disorders with an unknown and occult aetiology. ${ }^{1}$ Although MRI has greatly improved our ability to uncover anatomical lesions in these patients, ${ }^{2}$ our ignorance of a presumed cause may be due to low sensitivity of our diagnostic tools.

The assessment of cerebral metabolism by PET with $\left[{ }^{18} \mathrm{~F}\right]-2$-fluoro-2-deoxy-D-glucose $\left(\left[{ }^{18} \mathrm{~F}\right] \mathrm{FDG}\right)$ has improved our knowledge on the metabolism in the epileptogenic zone and on the pattern of diffusion of the epileptic discharge in different types of epilepsies. ${ }^{3-6}$ Indeed, PET $/\left[{ }^{18} \mathrm{~F}\right] \mathrm{FDG}$ now has a well established clinical role in the presurgical evaluation of patients with drug resistant temporal lobe epilepsy. ${ }^{7-9}$ Temporal lobe epilepsy is often symptomatic of cerebral lesions which are commonly found by MRI, ${ }^{10}$ but are sometimes detectable only by PET/ $\left[{ }^{18} \mathrm{~F}\right] \mathrm{FDG} .{ }^{10}$

Different mechanisms of origin and diffusion of the epileptic discharge may underlie symptomatic and cryptogenic temporal lobe epilepsies. The assessment of cerebral metabolism in patients with cryptogenic temporal lobe epilepsy could help to understand the physiopathological mechanisms of this type of seizure and eventually to reclassify individual patients.

The purpose of this study was the assessment of interictal regional cerebral glucose utilisation (rCMRglu) in patients not taking drugs and in whom the clinical diagnosis of cryptogenic epilepsy was made for the first time just before the study. Thus we investigated the early phases of cryptogenic temporal lobe epilepsy and avoided the possibility of artifactual findings due to the effects of antiepileptic treatment.

\section{Subjects and methods}

PATIENTS

We studied 13 consecutive patients (10 women and three men, mean age $31 \cdot 8$, range 17-53 years) in whom the diagnosis of cryptogenic temporal lobe epilepsy was made according to standard criteria (table 1). ${ }^{1}$

None of the patients with temporal lobe epilepsy had ever had a diagnosis of epilepsy before the enrolment in the study, not even those with a long history of disease, probably because of the little impact on their daily life of rare and benign partial seizures. For this reason they had never been treated with antiepileptic drugs.

Their first seizure occurred between six months and 27 years before the diagnosis (mean 4 (SD 7) years) and they reported a variable number of seizures (mean 8 (SD 12); range 3-50) during the entire course of the disease.

Eleven patients had only complex partial 
Table 1 Clinical features of patients with temporal lobe epilepsy

\begin{tabular}{|c|c|c|c|c|c|}
\hline $\begin{array}{l}\text { Patient } \\
\text { No }\end{array}$ & Sex & Age & $\begin{array}{l}\text { Duration } \\
\text { of disease (y) }\end{array}$ & $\begin{array}{l}\text { Type of } \\
\text { seizures }\end{array}$ & $E E G$ focus \\
\hline $\begin{array}{r}1 \\
2 \\
3 \\
4 \\
5 \\
6 \\
7 \\
8 \\
9 \\
10 \\
11 \\
12 \\
13\end{array}$ & $\begin{array}{l}\mathrm{F} \\
\mathrm{F} \\
\mathrm{M} \\
\mathrm{F} \\
\mathrm{F} \\
\mathrm{F} \\
\mathrm{M} \\
\mathrm{F} \\
\mathrm{F} \\
\mathrm{F} \\
\mathrm{M} \\
\mathrm{F} \\
\mathrm{F}\end{array}$ & $\begin{array}{l}26 \\
28 \\
48 \\
27 \\
17 \\
24 \\
53 \\
24 \\
20 \\
23 \\
47 \\
41 \\
40\end{array}$ & $\begin{array}{c}0 \cdot 5 \\
1 \\
1 \\
4 \\
1 \\
3 \\
27 \\
5 \\
0 \cdot 5 \\
0 \cdot 5 \\
4 \\
3 \\
10\end{array}$ & $\begin{array}{l}C P \\
C P+\text { gen } \\
C P \\
C P+\text { gen } \\
C P \\
C P+S P \\
C P+\text { gen } \\
C P \\
C P+\text { gen } \\
C P \\
S P+g e n \\
C P+S P \\
S P+\text { gen }\end{array}$ & $\begin{array}{l}\text { T left } \\
\text { Bitemporal } \\
\text { T left } \\
\text { T left } \\
\text { T right } \\
\text { T left } \\
\text { T right } \\
\text { T left } \\
\text { Bitemporal } \\
\text { T left } \\
\text { T right } \\
\text { T right } \\
\text { T right }\end{array}$ \\
\hline
\end{tabular}

$\overline{\mathrm{CP}}=$ Complex partial seizures; $\mathrm{SP}=$ simple partial seizures; gen $=$ secondarily generalised seizures; $\mathrm{T}=$ temporal lobe.

seizures and two patients had both simple and complex partial seizures. Six patients reported one to three episodes of secondary generalisation, usually during sleep. Interictal waking or sleep EEG recordings showed epileptic abnormalities localised in the left (six patients), in the right (five patients), or in both (two patients) temporal regions. An ictal EEG could not be recorded in any of the patients examined.

None of the patients had relevant neurological or systemic disease, and brain MRI was normal; MRI was performed with a 1.5 Tesla superconducting unit, using contiguous axial and coronal slides of $5 \mathrm{~mm}$ thickness and multiple spin echo sequences $(T R=2400 \mathrm{~ms} ; \mathrm{T} 1=500 / 17 \mathrm{~ms}$; $\mathrm{T} 2=15 / 90 \mathrm{~ms}$ ). Because the accuracy of MRI evaluation is critical in the diagnosis of cryptogenic temporal lobe epilepsy, an expert unblind neuroradiologist was asked to rule out possible structural abnormalities in the mesial temporal lobe.

Patients underwent the PET/ $\left[{ }^{18} \mathrm{~F}\right] \mathrm{FDG}$ study at least three days after their last seizure. Scalp EEG monitoring, initiated at least 30 minutes before giving $\left[{ }^{18} \mathrm{~F}\right] \mathrm{FDG}$, and carried out up to the end of the PET examination, did not show subclinical seizures or epileptic patterns other than those in the patients' previous EEG recordings.

\section{CONTROLS}

Control subjects were 13 normal healthy age matched volunteers, mean age $34 \cdot 2$, range $18-59$ years, and with no history of drugs or seizures.

Permission for the study was given by the ethics committee of the Scientific Institute $\mathrm{H}$ San Raffaele.

\section{PET METHODS}

The $\left[{ }^{18} \mathrm{~F}\right] \mathrm{FDG}$ was synthesised as previously described ${ }^{11}$ with a compact automated module connected to the cyclotron (Siemens-CTI RDS 112 cyclotron, Siemens/CPS, Knoxville, TN, USA) and used within one hour of its preparation. Quality control procedures for the tracers were carried out routinely according to methods previously described and $\left[{ }^{18} \mathrm{~F}\right]$ FDG with radiochemical purity higher than $95 \%$ was used. ${ }^{12}$ We used an ECAT 931/04-12 tomograph (CPS/Siemens, Knoxville, TN, USA) with a transverse field of view of $55.5 \mathrm{~cm}$ and an axial field of view of $5.4 \mathrm{~cm}$. All subjects were studied in the resting state with their eyes open and ears unplugged. Before each study a 20 gauge teflon catheter was inserted into the radial artery, under local anaesthesia; the patients were then positioned in the PET scanner and their heads were restrained by a customised head holder. The orbitomeatal line was symmetrically defined with the aid of low energy laser beams and skin marks and the PET gantry was aligned to obtain axial slices parallel to the orbitomeatal line. Two 10 minute consecutive transmission scans, one for each bed position necessary to examine the whole brain, were performed with a ${ }^{68} \mathrm{Ge} /{ }^{68} \mathrm{Ga}$ source external to the subject to measure the coefficients to correct for attenuation of the emitted photons. At the end of the transmission scan each subject received an intravenous injection of about $250 \mathrm{MBq}$ of $\left[{ }^{18} \mathrm{~F}\right]$ FDG. Timed arterial blood samples were collected continuously for the first minute after the tracer injection and then at increasing intervals throughout the PET study, to assay the plasma concentration of glucose and ${ }^{18} \mathrm{~F}$. Emission scans were carried out between 45 and 70 minutes after intravenous $\left[{ }^{18} \mathrm{~F}\right] \mathrm{FDG}$ injection. Data were acquired from two sets of seven equally spaced transaxial planes (four direct and three cross planes; slice thickness $6.75 \mathrm{~mm}$ ) parallel to the orbitomeatal line and covering an axial field of view of $10 \cdot 8 \mathrm{~cm}$. Scans were reconstructed with a Hann Filter with a cut off frequency of 0.5 cycles per pixel. Under these conditions, the spatial resolution in the image plane was $8 \mathrm{~mm}$ full width at half maximum. Each image was reconstructed on a $128 \times 128$ matrix with a pixel size of $1.56 \mathrm{~mm}$. Correction for attenuation of the $512 \mathrm{KeV} \gamma$ rays by the tissue was performed with the coefficients obtained from the transmission scan. Average values of regional cerebral metabolic rate for glucose (rCMRglu) were calculated in each region of interest based on the plasma glucose and ${ }^{18} \mathrm{~F}$ assays according to a model with the three rate constants operational equation of Sokoloff $e t a l^{12}$ using the kinetic constants and lumped constant reported by Reivich et al. ${ }^{13}$

\section{PET DATA ANALYSIS}

Reconstructed images were transferred to a SUN SPARC workstation for the analysis. Circular regions of interest, with a diameter of $9.6 \mathrm{~mm}$ ( 1.5 full width at half maximum), were drawn on 14 anatomofunctional cortical, subcortical, and cerebellar structures, identified from the atlas of Damasio and Damasio. ${ }^{14}$ Mean rCMRglu values for each of the 14 structures were calculated by averaging the rCMRglu values of the multiple regions of interest included in each anatomical region. These average values were used for the data analysis.

STATISTICAL ANALYSIS

All analyses were with the SPSS package. ${ }^{15}$

$A$ repeated measures analysis of variance 
(ANOVA) with one between subject factor (temporal lobe epilepsy patients $v$ normal controls) and two within subject factors (cerebral regions (the 14 regions listed in table 2) and hemisphere (left and right)) was performed. The mean and interaction effects, when significant, were tested with the appropriate univariate ANOVA and further analysed with Bonferroni's correction for multiple comparisons set at $P<0.05$.

To remove the potential confounding effect of within and between subject variation of global hemispheric activity on rCMRglu in the post hoc analyses, we used univariate analyses of covariance (ANCOVA). The adequacy of the covariate model for each region was tested evaluating the homogeneity of slopes assumption (parallelism of covariate between groups)..$^{16}$

A stepwise feed forward discriminant function analysis was used to provide additional information about which metabolic variables were most efficient at differentiating patients with temporal lobe epilepsy from normal controls. The discriminant function analysis is a multivariate linear method which examines a series of dependent variables (rCMRglu) of two or more groups, calculates the "discriminant score", and, on the basis of that, enables the classification of individual subjects within each group. Only those variables which met the criterion of an 0.05 level of significance were entered into the equation. The classification accuracy was determined when all the variables had been selected.

Non-parametric Kendall's tau rank correlations with corrections for tied values were used to assess the relation between clinical scores and regional metabolic rates.

\section{Results}

rCMRglu IN THE TEMPORAL LOBE EPILEPSY GROUP V CONTROL GROUP

Table 2 summarises the mean rCMRglu values measured in the two hemispheres and in 14 discrete cerebral regions, in patients with temporal lobe epilepsy and controls.
A significant group effect $(F(1,48)=15.61, \mathrm{P}<0.001)$ and a regional effect $(F(13,312)=187.30, \quad P<0.0001)$, but no significant hemispheric effect $(F(1,48)$ $=0 \cdot 05, \mathrm{NS})$ were shown by a repeated measures ANOVA. The group $\times$ regions interaction was significant $(F(13,312)=7 \cdot 04$, $\mathbf{P}=0.0001)$, thus indicating a different rCMRglu between patients and controls. No other significant interactions were found.

The post hoc analysis of regional differences showed a significant bilateral increase of metabolic activity in the lateral $(P<0.0002)$ and polar $(P<0.0004)$ temporal regions, in the thalamus $(P<0.002)$, caudate $\quad(P<0.002)$, pallidum/putamen complex $(P<0.002)$, and anterior cingulate cortex $(P<0.002)$.

The significant differences in the post hoc analyses were confirmed even when the effect of global hemispheric activity on rCMRglu was removed by covariance (table 2 ).

The stepwise discriminant function analysis identified six regions the metabolism of which showed the greatest statistical power in discriminating between patients with temporal lobe epilepsy and normal controls. These areas constituted a bilateral network including lateral and polar temporal regions, lateral frontal regions, thalami, caudates, and anterior cingulate cortices (Wilks' Lambda: $\mathbf{0 \cdot 2 4}$, $F=23.71 ; \mathrm{P}<0.00001)$.

\section{MEASURES OF METABOLISM IN INDIVIDUAL} PATIENTS WITH TEMPORAL LOBE EPILEPSY No significant correlations were found between rCMRglu and sex, age, side of EEG abnormalities, duration of disease, and types and number of seizures. No patients had regional or hemispheric hypometabolism below the 5 th percentile of controls.

\section{Discussion}

In a group of patients with cryptogenic temporal lobe epilepsy who were never treated with antiepileptic drugs, we have found evidence of significant interictal hypermetabo-

Table 2 rCMRglc $\left(m g 100 g^{-1} \min ^{-1}\right)$ in patients $(n=13)$ and controls $(n=13)$

\begin{tabular}{|c|c|c|c|c|c|c|c|c|}
\hline & \multicolumn{4}{|l|}{ Left hemisphere } & \multicolumn{4}{|l|}{ Right hemisphere } \\
\hline & $T L E$ patients & Controls & $\begin{array}{l}F \\
\text { value }\end{array}$ & $\begin{array}{l}\text { ANCOVA } \\
\text { valuet }\end{array}$ & TLE patients & Controls & $\begin{array}{l}F \\
\text { value }\end{array}$ & $\begin{array}{l}\text { ANCOVA } \\
\text { valuet }\end{array}$ \\
\hline $\begin{array}{l}\text { Hemisphere } \\
\text { Frontal: }\end{array}$ & $6.81(0.86)(6.29-7.33)$ & $6.07(0.60)(5.70-6.43)$ & $7 \cdot 95$ & - & $6 \cdot 78(0 \cdot 75)(6 \cdot 32-7 \cdot 23)$ & $6.08(0.57)(5.73-6.42)$ & $6 \cdot 73$ & - \\
\hline $\begin{array}{l}\text { Basal } \\
\text { Lateral } \\
\text { Rolandic } \\
\text { Cingulate } \\
\text { Parietal } \\
\text { Temporal: }\end{array}$ & $\begin{array}{l}6.49(0.86)(5.97-7.02) \\
7.01(0.87)(6.48-7.54) \\
6.92(0.71)(6.49-7.30) \\
7.01(0.87)(6.48-7.53) \\
6.96(0.90)(6.41-7.50)\end{array}$ & $\begin{array}{l}5.90(0.45)(5.62-6.17) \\
6.22(0.62)(5.84-6.59) \\
6.49(0.64)(6.10-6.88) \\
5.95(0.76)(5.49-6.40) \\
6.26(0.58)(5.95-6.58)\end{array}$ & $\begin{array}{c}4 \cdot 80 \\
7 \cdot 29 \\
2 \cdot 40 \\
12 \cdot 42^{\star} \\
5 \cdot 87\end{array}$ & $\begin{array}{c}2 \cdot 84 \\
4 \cdot 16 \\
1 \cdot 64 \\
11 \cdot 22^{\star} \\
4 \cdot 42\end{array}$ & $\begin{array}{l}6.41(0.83)(5.91-6.91) \\
6.92(0.80)(6.43-7.40) \\
6.89(0.76)(6.42-7.35) \\
6.82(0.81)(6.33-7.31) \\
6.90(0.81)(6.41-7.39)\end{array}$ & $\begin{array}{l}5.82(0.46)(5.54-6.10) \\
6.19(0.68)(5.77-6.60) \\
6.48(0.70)(6.06-6.91) \\
5.90(0.59)(5.54-6.26) \\
6.39(0.61)(6.01-6.76)\end{array}$ & $\begin{array}{c}4 \cdot 90 \\
6 \cdot 12 \\
2 \cdot 09 \\
11 \cdot 83^{\star} \\
3 \cdot 18\end{array}$ & $\begin{array}{c}2 \cdot 65 \\
4 \cdot 10 \\
1 \cdot 47 \\
10 \cdot 55^{\star} \\
3.94\end{array}$ \\
\hline $\begin{array}{l}\text { Polar } \\
\text { Lateral } \\
\text { Mesial } \\
\text { Occipital: }\end{array}$ & $\begin{array}{l}5.05(0.66)(4.65-5.43) \\
6.78(0.73)(6.34-7.23) \\
5.93(0.79)(5.45-6.41)\end{array}$ & $\begin{array}{l}4.27(0.57)(3.92-4.61) \\
5.77(0.47)(5.48-6.05) \\
5.29(0.56)(4.95-5.63)\end{array}$ & $\begin{array}{l}14 \cdot 39^{\star} \\
20 \cdot 18^{\star} \\
6 \cdot 73\end{array}$ & $\begin{array}{c}9 \cdot 38^{\star} \\
20 \cdot 35^{\star} \\
3 \cdot 21\end{array}$ & $\begin{array}{l}5.04(0.53)(4 \cdot 72-5.36) \\
6.66(0.60)(6.30-7.03) \\
5.75(0.58)(5.40-6 \cdot 11)\end{array}$ & $\begin{array}{l}4 \cdot 26(0.43)(4 \cdot 12-4 \cdot 40) \\
5.76(0.44)(5.49-6.03) \\
5.27(0.53)(4.95-5 \cdot 60)\end{array}$ & $\begin{array}{c}14 \cdot 25^{\star} \\
15 \cdot 94^{\star} \\
5 \cdot 75\end{array}$ & $\begin{array}{c}9 \cdot 97^{\star} \\
18 \cdot 13^{\star} \\
3.08\end{array}$ \\
\hline $\begin{array}{l}\text { Lateral } \\
\text { Calcarine } \\
\text { 2utamen/ }\end{array}$ & $\begin{array}{l}6.44(0.62)(6.06-6.82) \\
8.03(1.15)(7.34-8.73)\end{array}$ & $\begin{array}{l}6 \cdot 35(0.72)(5 \cdot 91-6 \cdot 78) \\
7 \cdot 23(0.90)(6 \cdot 68-7 \cdot 78)\end{array}$ & $\begin{array}{l}0 \cdot 25 \\
2 \cdot 97\end{array}$ & $\begin{array}{l}2.51 \\
1.86\end{array}$ & $\begin{array}{l}6.46(0.62)(6.08-6.83) \\
7.69(1.13)(7.00-8.38)\end{array}$ & $\begin{array}{l}6.45(0.91)(5.90-7 \cdot 01) \\
7.68(0.89)(6.60-7.68)\end{array}$ & $\begin{array}{l}0 \cdot 82 \\
1 \cdot 80\end{array}$ & $\begin{array}{l}2.58 \\
1.98\end{array}$ \\
\hline $\begin{array}{l}\text { pallidum } \\
\text { Caudate } \\
\text { Thalamus } \\
\text { Cerebellum }\end{array}$ & $\begin{array}{l}7 \cdot 68(0 \cdot 85)(7 \cdot 16-8 \cdot 19) \\
7 \cdot 30(0 \cdot 65)(6 \cdot 90-7 \cdot 69) \\
7 \cdot 22(0 \cdot 81)(6 \cdot 73-7 \cdot 70) \\
6 \cdot 04(0 \cdot 70)(5 \cdot 61-6 \cdot 46)\end{array}$ & $\begin{array}{l}6 \cdot 57(0.72)(6 \cdot 13-7.01) \\
6 \cdot 26(0.58)(5 \cdot 91-6.61) \\
6 \cdot 21(0.73)(5 \cdot 77-6.66) \\
5.40(0.68)(4.99-5 \cdot 81)\end{array}$ & $\begin{array}{c}12 \cdot 15^{\star} \\
15 \cdot 09^{\star} \\
10 \cdot 76^{\star} \\
2 \cdot 99\end{array}$ & $\begin{array}{c}10 \cdot 31^{\star} \\
10 \cdot 43^{\star} \\
9 \cdot 38^{\star} \\
1 \cdot 26\end{array}$ & $\begin{array}{l}7.51(0.96)(6.92-8.09) \\
7 \cdot 17(0.70)(6.74-7.59) \\
7.33(0.83)(6.83-7.84) \\
6.02(0.65)(5.62-6.41)\end{array}$ & $\begin{array}{l}6.60(0.56)(6.23-6.93) \\
6 \cdot 36(0.60)(5.99-6.72) \\
6 \cdot 28(0.76)(5 \cdot 82-6 \cdot 74) \\
5.40(0.62)(5 \cdot 03-5 \cdot 78)\end{array}$ & $\begin{array}{c}10 \cdot 18^{\star} \\
10 \cdot 93^{\star} \\
10 \cdot 10^{\star} \\
2 \cdot 56\end{array}$ & $\begin{array}{l}9 \cdot 88^{\star} \\
9 \cdot 87^{\star} \\
9 \cdot 89^{\star} \\
1 \cdot 74\end{array}$ \\
\hline
\end{tabular}

Values are means (SD) (95\% CI); TLE = temporal lobe epilepsy.

TF values adjusted for global hemispheric metabolism (one way ANCOVA)

$\star$ Significance level set at $P<0.003$ according to Bonferroni's correction. 
lism in a bilateral neural network including the temporal lobes, thalami, basal ganglia, and cingular cortices. Applying the metabolism of these areas and of lateral frontal regions in the model of discriminant function analysis, all patients with temporal lobe epilepsy and normal controls could be correctly assigned to each category. Although lacking stringent statistical significance, several other cortical areas had bilateral increases of rCMRglu ranging from $10 \%$ to $15 \%$. These areas were the frontal basal, frontal lateral, temporal mesial, and cerebellar cortices, all of which are known to be functionally correlated to the significantly hypermetabolic network. By contrast, the rolandic, parietal, and occipital areas showed minimal increases, ranging from $0.5 \%$ to $7 \%$ in comparison with normal subjects.

This finding is surprising because previous interictal studies of patients with refractory temporal lobe epilepsy have shown in most cases unilateral areas of temporal hypometabolism, usually concordant with the side of the EEG abnormalities and with the site of a morphological lesion. ${ }^{17}$ Interictal hypermetabolism has been occasionally reported: in episodic cases of children with refractory temporal lobe epilepsy, ${ }^{18}$ bilaterally in lenticular nuclei of children with infantile spasms, ${ }^{5}$ and in the thalamus contralateral to mesial gliosis in patients with refractory temporal lobe epilepsy. ${ }^{19}$ On the contrary, a widespread hypermetabolism is usually found during seizures or in the postictal period in patients with refractory temporal lobe epilepsy. ${ }^{31718}$ Hypermetabolism due to seizures can be reasonably excluded in our patients as they had been seizure free for at least three days before the PET $/\left[{ }^{18} \mathrm{~F}\right] \mathrm{FDG}$ study. Moreover, EEG monitoring excluded seizures 30 minutes before and during the PET/ $\left[{ }^{18} \mathrm{~F}\right]$ FDG study. The unlikely possibility of a localised subclinical discharge in the mesial structures undetected by scalp EEG cannot be ruled out.

The apparent discrepancies between these and previous findings can have several explanations. The population of epileptic patients examined in this study was different from those previously examined. In particular, our patients: (a) had a diagnosis of cryptogenic and not of symptomatic temporal lobe epilepsy; (b) had a mild illness; (c) were not taking medication. Patients with cryptogenic epilepsies are less commonly drug resistant and less severely ill than patients with symptomatic epilepsies. Abnormal MRI findings, including mesial gliosis or neoplasms, are often found in patients with refractory temporal lobe epilepsy. These patients, often with long lasting, frequent, and severe seizures, may have had a spontaneous kindling phenomenon, or even sequelae of cerebral trauma, further complicating cerebral metabolic patterns. Patients with cryptogenic temporal lobe epilepsy and normal MRI may have a pattern of origin and diffusion of epileptogenic discharges different from that of patients with temporal lobe epilepsy refractory to antiepileptic drugs. All patients with refractory temporal lobe epilepsy studied with PET $/\left[{ }^{18} \mathrm{~F}\right] \mathrm{FDG}$ and reported in the medical literature were having long term antiepileptic treatment, often with more than one drug. This was likely to induce a decrease in cerebral glucose metabolism. ${ }^{20}$

Our finding of a bilateral hypermetabolic network contrasts with the hypothesis of well localised epileptogenic zones underlying the pathophysiology of cryptogenic temporal lobe epilepsy. This pattern is, however, in agreement with the clinical finding that often in cryptogenic temporal lobe epilepsy neither seizure phenomenology nor EEG are clearly lateralising or localising the epileptogenic zone. For example, in our sample no patient had lateralising signs in their seizures (which were mainly amygdalohippocampal ${ }^{1}$ and secondarily generalised), two patients out of 13 had bilateral EEG abnormalities, and six patients showed lateralising EEGs only during sleep recordings.

The bilateral hypermetabolic network found in a group of untreated patients with cryptogenic temporal lobe epilepsy could represent a pathophysiological state of hyperactivity predisposing to epileptic discharge generation or diffusion, or a network of inhibitory circuits activated to prevent the diffusion of the epileptic discharge originating from a localised epileptogenic zone. In refractory symptomatic temporal lobe epilepsy, focal neuronal loss and gliosis or alterations of synaptic processes seem to be the common causes of interictal glucose hypometabolism, ${ }^{21}$ whereas the ictal hypermetabolism could be related to energy consuming epileptic activity. ${ }^{317}$ Postictal hypermetabolism seems to be due to energy expenditure of inhibitory circuits for the restoration of normal membrane polarisation and chemical homeostasis. A similar mechanism could explain our finding of hypermetabolic bilateral networks in patients with cryptogenic temporal lobe epilepsy. Against this hypothesis are the low frequency of their seizures, the mildness of the disease, and the long time (at least 72 hours) between the last seizure and the PET $/\left[{ }^{18} \mathrm{~F}\right] \mathrm{FDG}$ study. The hypothesis that the hyperactive network is the underlying pathophysiological basis of the disease seems to be more reasonable and could be confirmed by an ongoing follow up study in the same group of patients during chronic effective treatment with carbamazepine. Indeed, it cannot be ruled out that hypermetabolic networks may actually underlie most epileptic processes and could also be found in patients with refractory temporal lobe epilepsy if it were possible to study them when they were not taking drugs.

Whichever is the neurophysiological interpretation, the finding of a hypermetabolic network in cryptogenic temporal lobe epilepsy suggests the existence of different mechanisms of origin and diffusion of the epileptic discharge and of different functional balance between "normal" and "lesioned" cerebral areas in different types of epilepsies. This in turn points out the need for metabolic 
studies in other types of epilepsies, such as idiopathic epilepsies or situation related epileptic syndromes.

1 Commission on Classification and Terminology of the International League against Epilepsy. Proposal for revised classification of epilepsies and epileptic syndromes. Epilepsia 1989;30:389-99.

2 Franceschi M, Triulzi F, Ferini-Strambi L, et al. Focal cerebral lesions found by magnetic resonance imaging in cryptogenic nonrefractory temporal lobe epilepsy in cryptogenic nonrefractory ter.

3 Engel J Jr, Kuhl DE, Phelps ME. Patterns of human local glucose metabolism during epileptic seizures. Science glucose metabolist

4 Chugani HT, Mazziotta JC, Engel J Jr, et al. The LennoxGastaut syndrome: metabolic subtypes determined by 2-deoxy-2(F18)-fluoro-D-glucose positron emission tomography. Ann Neurol 1987;21:4-13.

5 Chugani HT, Shewmon DA, Sankar A, et al. Infantile spasms: II. Lenticular nuclei and brain stem activation on positron emission tomography. Ann Neurol 1992;31: 212-9.

6 Henry TR, Mazziotta JC, Engel J Jr. Interictal metabolic anatomy of mesial temporal epilepsy. Arch Neurol 1993;50:582-9.

7 Chugani HT, Shewmon DA, Peackock WJ, et al. Surgical treatment of intractable neonatal-onset seizures: the role of positron emission tomography. Neurology 1988;38: of positro

8 Engel J Jr, Henry TR, Risinger MW, et al. Presurgical evaluation for partial epilepsy: relative contributions of chronic depth-electrode recordings versus FDG-PET and scalp sphenoidal ictal EEG. Neurology 1990;40: 1670-7.

9 Swartz BE, Tomiyasu U, Delgado-Escueta AV, et al. Neuroimaging in temporal lobe epilepsy: test sensitivity and relationships to pathology and postoperative outcome. Epilepsia 1992;33:624-34

10 Valk PE, Laer KD, Barbaro NM, et al. High-resolution $(2.6 \mathrm{~mm}) \mathrm{PET}$ in partial complex epilepsy associated with mesial temporal sclerosis. Radiology 1993;186: with

11 Hamacher K, Coenen HH, Stocklin G. Efficient stereospecific synthesis of no-carrier-added $2-\left[{ }^{18} \mathrm{~F}\right]$ fluoro-2deoxy-D-glucose using aminopolyether supported nucleophilic substitution. $f$ Nucl Med 1986;27:235-8.

12 Sokoloff L, Reivich M, Kennedy C, et al. The (C14)deoxyglucose method for the measurement of local cerebral glucose utilization: theory, procedures and normal values in the conscious and anesthetized albino rat. F Neurochem 1977;28:897-916.

13 Reivich M, Alavi A, Wolf A, et al. Glucose metabolic rate kinetic model parameter determination in humans: the lumped constants and rate constants for (F18) fluorodeoxyglucose and (C11) deoxyglucose. I Cereb Blood Flow Metab 1985;5:179-92.

14 Damasio H, Damasio AR. Lesion analysis in neuropsychology. New York: Oxford University Press, 1989.

15 Nie N, Hull CH, Jenkins JC, Steinbrenner K, et al. SPSS statistical package for the social services. 2nd ed. New York: McGraw-Hill, 1975.

16 Winer BJ. Statistical principles in experimental design. 2nd ed. New York: McGraw-Hill, 1971.

17 Engel J Jr, Kuhl DE, Phelps ME, et al. Local cerebra metabolism during partial seizures. Neurology 1983;33: 400-13.

18 Chugani HT, Shewmon DA, Khanna S, et al. Interictal and postictal hypermetabolism on positron emission tomography. Pediatr Neurol 1993;9:10-5.

19 Khan N, Hajek M, Wieser HG, et al. Interictal thalamic glucose metabolism in temporal lobe epilepsy. Neurology glucose metabolisn

20 Theodore WH. Antiepileptic drugs and cerebral glucose metabolism. Epilepsia 1988;29(suppl 2):S48-S55.

21 Sackellares JC, Siegel GJ, Abou-Khalil BW, et al. Differences between lateral and mesial temporal metabolism interictally in epilepsy of mesial temporal origin. Neurology 1990;40:1420-6. 